\title{
Lick rate development in infant Mongolian gerbils
}

\author{
STEPHEN C. PIERSON \\ University of Minnesota, St. Paul, Minnesota 55101 \\ and \\ ROBERT W. SCHAEFFER \\ Auburn University, Auburn, Alabama 36830
}

\begin{abstract}
Lick rates in two male and two female Mongolian gerbils (Meriones unguiculatus) were measured over a 39-day period during which the gerbils aged from 21 to 60 days. The data confirmed previous data by showing that infant lick rates differ from adult lick rates. Contrary to previous data, however, infant gerbils were found to exhibit more lick rate variability and to lick both more rapidly and more slowly than adult gerbils.
\end{abstract}

There exists a body of evidence which indicates that in several mammals the licking response occurs at a relatively constant rate and is independent of sex, deprivation level, and type of solution ingested. This phenomenon has been demonstrated in rats (Davis \& Keehn, 1959; Stellar \& Hill, 1952); cats (Schaeffer \& Huff, 1965); rabbits (Schaeffer \& David, 1973b), and hamsters (Pierson \& Schaeffer, 1974). In addition, Pierson and Schaeffer (1973) have presented clear evidence that licking rates that are in excess of normally occurring rates cannot be conditioned using DRH procedures, which differentially reinforce only high rates of responding.

More important for the present investigation, however, is the finding by Schaeffer and Premack (1961) that neonatal rats, raised from birth to weaning without an opportunity to drink, upon their first contact with fluids, displayed a mean lick rate comparable to that of adults. Lick rates in infant Mongolian gerbils at weaning age, however, have not been found to be characteristic of adult gerbil lick rates (Schaeffer \& David, 1973a). The present experiment was undertaken to determine the age at which the licking response of the infant gerbil takes on the characteristics of the adult licking response.

\section{METHOD}

\section{Subjects}

Subjects were two male and two female Mongolian gerbils (Meriones unguiculatus), all experimentally naive and 21 days old at the beginning of testing. All subjects had previously received all fluids via nursing and, prior to weaning at 21 days of age, had no experience with drinking tubes. Purinal Lab Chow, rolled oats, and cereals were provided ad lib before and after weaning.

\section{Apparatus and Procedure}

The subjects were housed individually in $.9525-\mathrm{cm}$ Plexiglas

The research for this paper was supported by Public Health Research Grants MH08775 and MH-12025 from the National Institute of Mental Health, R. W. Schaeffer, principal
investigator. test chambers $(20.32 \times 20.32 \times 20.32 \mathrm{~cm})$ with a wire-mesh top and an aluminum drinking platform. Standard stainless steel watering nipples, coated with an electric insulated compound (Formvar) to provide electrical continuity only through the solution, were inserted $5.08 \mathrm{~cm}$ into the chamber and $2.54 \mathrm{~cm}$ above the platform. Lehigh Valley Electronics Model 1520 drinkometer circuits were used to sense tongue-fluid contacts. Each tongue lap was recorded by an Esterline-Angus digital recorder on tape moving at $1.905 \mathrm{~cm} / \mathrm{sec}$.

Lick rates for tap water were obtained continually throughout each day until the gerbils reached 60 days of age. Initiation of a drinking bout by any subject started the Esterline-Angus tape moving. The initial tongue-tube contact and each subsequent lick were programmed to keep the tape moving for a 10 -sec period. Thus, following the last lick in each lick burst, independently of whether only one or all four subjects were licking, the Esterline-Angus continued to run for $10-\mathrm{sec}$.

\section{RESULTS AND DISCUSSION}

Lick rates were analyzed using the procedures described by Schaeffer and Premack (1961). The specific lick rates obtained were as follows: (1) momentary lick rates, obtained from a second-by-second analysis of all recorded licks in a session, (2) mean lick rates obtained only from sustained bursts of licking that were at least $3 \mathrm{sec}$ in duration, and (3) changes in momentary rates within sustained bursts of licking.

These results, summarized in Table 1 , indicated that until about 34 days of age, infant gerbils exhibit mean lick rates that are either slower or slightly in excess of those rates found to occur after that age. Throughout the 21 to 34 day period, the variability in the lick rate, as indicated by the lick rate ranges obtained, was substantial. At 35 days of age, however, in three subjects, the licking response acquired rate characteristics typical of adult gerbils. By 42 days of age, all four infant gerbils showed lick rates typical of adult gerbils and were emitting burst of $15-20$ sec duration, with some bursts as long as $45-50 \mathrm{sec}$. Prior to this time, the lick bursts were shorter than $15 \mathrm{sec}$ and did not have the characteristic interlick intervals found in adult 
Table 1

Mean Lick Rates and Ranges for 1-Sec Measures and Bursts of 3 Sec or More

\begin{tabular}{|c|c|c|c|c|c|c|c|c|c|}
\hline \multirow[b]{2}{*}{ Subject } & \multirow{2}{*}{$\begin{array}{c}\text { Measure } \\
\text { (in sec) }\end{array}$} & \multicolumn{2}{|c|}{ 21-27 } & \multicolumn{4}{|c|}{ Age in Days } & \multicolumn{2}{|c|}{$42-55$} \\
\hline & & Mean & Range & Mean & Range & Mean & Range & Mean & Range \\
\hline Male & $\begin{array}{l}1 \\
3\end{array}$ & $\begin{array}{l}6.0 \\
5.9\end{array}$ & $\begin{array}{l}4.0-7.0 \\
4.0-7.0\end{array}$ & $\begin{array}{l}7.1 \\
6.8\end{array}$ & $\begin{array}{l}7.0-8.0 \\
6.0-7.0\end{array}$ & $\begin{array}{l}6.0 \\
5.5\end{array}$ & $\begin{array}{l}5.0-7.0 \\
5.0-6.0\end{array}$ & $\begin{array}{l}6.1 \\
5.7\end{array}$ & $\begin{array}{l}5.0-6.0 \\
5.0-6.0\end{array}$ \\
\hline Male & $\begin{array}{l}1 \\
3\end{array}$ & $\begin{array}{l}6.2 \\
6.8\end{array}$ & $\begin{array}{l}3.0-8.0 \\
6.0-7.0\end{array}$ & 7.0 & 7.0 & 6.0 & 6.0 & $\begin{array}{l}6.0 \\
5.8\end{array}$ & $\begin{array}{l}6.0 \\
5.0-6.0\end{array}$ \\
\hline Female & $\begin{array}{l}1 \\
3\end{array}$ & $\begin{array}{l}7.0 \\
7.0\end{array}$ & $\begin{array}{l}6.0-9.0 \\
5.0-7.0\end{array}$ & & & $\begin{array}{l}6.0 \\
5.3\end{array}$ & $\begin{array}{l}6.0 \\
5.0-6.0\end{array}$ & $\begin{array}{l}5.9 \\
5.1\end{array}$ & $\begin{array}{l}5.0-6.0 \\
5.0-6.0\end{array}$ \\
\hline Female & $\begin{array}{l}1 \\
3\end{array}$ & $\begin{array}{l}6.0 \\
6.7\end{array}$ & $\begin{array}{l}3.0-11.0 \\
6.0-7.0\end{array}$ & $\begin{array}{r}10.0 \\
6.1\end{array}$ & $\begin{array}{l}4.0-13.0 \\
5.0-7.0\end{array}$ & $\begin{array}{l}5.9 \\
5.4\end{array}$ & $\begin{array}{l}5.0-7.0 \\
5.0-6.0\end{array}$ & $\begin{array}{l}6.0 \\
5.8\end{array}$ & $\begin{array}{l}6.0 \\
5.0-6.0\end{array}$ \\
\hline
\end{tabular}

gerbils. Lick rates as slow as 3 licks/sec and as rapid as 8-11 licks/sec were not uncommon within the same daily test session.

Visual observation of the subjects suggested that good muscular coordination of tongue movements was not present. Subjects, when initiating a drinking bout, were often noted to either not always contact the solution or not seem to be able to obtain water and swallow. After the gerbils were 35 days of age, however, momentary lick rates never exceeded $7 / \mathrm{sec}$, and lick rates of $7 / \mathrm{sec}$ were found only in the initial sec of a lick burst.

Obviously, the 35th day of life signaled an important date in the maturation of the lick response. Whether the lick rate changes observed at 35 days were the result of a learning process or more a physiological advance is not indicated by the present data. Further testing of naive 34-35-day-old gerbils should shed light on that particular issue, however.

Table 1 shows that, after 35 days, the mean momentary lick rates for all subjects were highly consistent. Maximum between subject variability for mean momentary lick rates was less than one lick per second. For all subjects, the lick rate obtained in the first second of each drink burst tended to be slightly higher than the mean momentary lick rate for the entire drinking burst. However, in contrast to results obtained from rats (Schaeffer \& Premack, 1961) within burst decrements in lick rates were very slight. Usually, lick rates did not change significantly after the initial second of licking, even when drinking bouts exceeded 20 sec.
In the present study, licking rates in the gerbils which were over 35 days of age were consistent with lick rates reported for cats, hamsters, rabbits, rats, and adult gerbils in that they depict very little variability. Infant gerbils, however, demonstrate considerable variability in their lick rates. This finding is compatable with the observation (Schaeffer \& David, 1973a) that infant and adult gerbil lick rates differ substantially.

Unlike Schaeffer and David's (1973a) data which showed only that infant gerbils lick at slower rates than adult rates, the present data show that infant gerbils lick at both slower and faster rates than adults. Current studies are in progress in our laboratories to determine the possible source of these differences.

\section{REFERENCES}

Davis, J. D., \& Keehn, J. D. Magnitude of reinforcement and consumatory behavior. Science, $1959,130,269-270$.

Pierson, S. C., \& Schaeffer, R. W. Differential reinforcement of specific lick rates in the rat. Bulletin of the Psychonomic Society, 1973, 2, 31-34.

Pierson, S. C., \& Schaeffer, R. W. Lick rates in hamsters. Bulletin of the Psychonomic Society, 1974, 3, 391-392.

Schaeffer, R. W. \& David, M. Lick rates in gerbils. Bulletin of the Psychonomic Society, 1973a, 2, 257-260.

Schaeffer, R. W., \& David, M. Lick rates in New Zealand white rabbits. Bulletin of the Psychonomic Society, 1973b, 2, 43-44.

Schaeffer, R. W., \& Huff, R. Lick rates in cats. Psychonomic Science, 1965, 3, 377-378.

Schaeffer, R. W., \& Premack, D. Licking rates in infant albino rats. Science, 1961, 134, 1980-1981.

Stellar, E., \& Hill, J. H. The rat's rate of drinking as a function of water deprivation. Journal of Comparative and Physiological Psychology, 1952, 45, 96-102.

(Received for publication October 23, 1974.) 